\title{
Business Warehouse Modeling Using SAP: Simulating A Business Case To Apply Strategic Enterprise Management To Accounting
}

Thomas A. Kramer, Saint Joseph's University, USA Joseph M. Ragan, Saint Joseph's University, USA Jonathan Gregory, Saint Joseph's University, USA Joseph Larkin, Saint Joseph's University, USA

\begin{abstract}
The goal of this research project is to develop a simulation model specifically for the Management Accounting Information Systems course - an SAP enabled course for junior Accounting majors at Saint Joseph's University. The purpose of this simulation is to present students with a set of business scenarios, and have the students make a knowledgeable decision using SAP Business Warehouse software. The scenarios will act as a simplified replication of the business environment; thus, they will provide the students with an integrated learning experience. They will make business decisions to ensure the profitability and cash flow of a corporation. While making these decisions, students participate in the application and analysis provided by PC4YOU, which is a simulated company within SAP for demonstration and education purposes. Eventually, the students will need to justify the existence of their strategic plans by evaluating benefits of the system using the reporting tools available within SAP. To provide a "learning by doing" experience, the scenarios will be used to demonstrate the reporting functionality within PC4YOU, the simulated company integrated into the SAP SEM system. Today's global economy is putting a premium on the ability of students to evaluate a broad range of decisions in collaboration with adaptive supply chains. A critical component of the evolving accounting curriculum lies in the ability to extend students beyond the numbers to evaluate the effective and efficient delivery of these supply chains.
\end{abstract}

\section{Introduction}

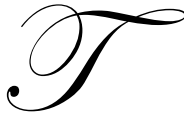

he principle of shareholder value is a continuous theme in the modern world of business. With global competition intensifying, enterprises need to find effective and efficient ways to optimize their shareholder value while doing commerce across countries and cultures. Pressure from investors to deliver sustaining returns has made shareholder value measurement a particularly critical goal of the modern enterprise.

Many enterprises now manage their multi-segments with Enterprise Resource Planning software. They have succeeded in making their operational business processes more efficient, effective and customer-orientated, which has increased their shareholder value. The outcome of ERP system implementations allows these enterprises to now gain a wealth of information that can be utilized to support strategic management processes. The guarantee that strategic decisions are actually converted into concrete operational objectives is a chronic conundrum of modern day business. To seize the fullest value of Enterprise Resource Planning software, many firms have integrated Strategic Enterprise Management (referred to in this paper as SEM) processes as a unifying function for all of their product units. It is in this way that an enterprise can align its activities with the value expectations of it's 
shareholders. Strategy has to move out of the back office and needs to be integrated into the day-to-day work of each employee, who can contribute their talents to make strategy happen and who can provide feedback for further optimization of the growth and development of the company.

This new value-based management enables organizations to implement performance, management and stakeholder communication based on a Balanced Scorecard concept. This paper examines how to translate strategy into action using SEM tools within SAP Software. Using the Strategy Enterprise Management model, we are able to expose students to the major applications and associated tools of corporate performance monitoring, which is an essential component of Balanced Scorecard reporting within SEM. This corporate monitoring provides immediate feedback on financial, non-financial, internal, and external measures.

\section{Prior Research}

Most of the underlying theory behind implementing an Information Warehouse with SEM capabilities stems from top management's desire to provide their organizations with a competitive advantage within their industry and elimination of redundancy from using several different systems (Davenport, 1998). An advantage cited by Whiteside is that, "it allows management to monitor goal achievement and benchmark performance." Additionally, Fahy notes that, "a knowledge management system with SEM capabilities empowers executives with information. In order to support the value creation process effectively, executives need information that allows them to identify changes in the market quickly and react with new strategies (Fahy, 2000)." From schools to universities, businesses to government, we have become a performance-assessed society (Humphrey and Owen, 2000; Power, 2000) absorbed with focusing on performance measures, which can affect organizational success and failure.

Information which is relevant to sales, profitable customers, performance drivers, competing firms, customer relations, research and development, and much more, all of which has been disaggregated and "analyzed" by the system, becomes instantly accessible using a SEM enabled system (Brignall, 1997). Kaplan and Norton (1992), have argued that to manage performance strategically and to ensure continuous improvement across multiple dimensions of performance requires that a process be built at, both, the planning and performance management stages. This means recognizing that alternative strategic plans have differing interactions and tradeoffs affecting performance dimensions and the choosing among the plans requires the tracing of their likely cause and effect across multiple performance dimensions (Doyle, 1994). The tracing of such chains of cause and effect can often be problematic and may be enhanced when such systems are operated within a Strategic Management System (Norreklit, 2000; Brignall, 2002).

Vendors of ERP Systems claim that their SEM Systems allow for timely informed corporate performance monitoring. This monitoring, "occurs in the planning, executing and controlling of business processes horizontally across the value-chain and vertically to support strategic management processes, such as: Strategic Planning, Risk Management, Performance Monitoring and Value Management (Norton, 1999)." Further, "SEM allows a two way flow of communication. Corporate Strategists can monitor performance continually using feedback from business modules, and adjustments of the strategies can be driven down to the operational level via new targets (Norton, 1999)." Fahy (2001) argues that the "SEM approach seeks to effectively link performance measurements and control to strategic objectives, in an attempt to ensure that operational decision-making is fully focused on delivering strategic objectives."

As SEM appears to be growing in popularity within the business world, it makes sense that business students be exposed to this new technology within their undergraduate curriculum. There are no studies to date that define a curriculum where SEM is even minimally covered.

\section{SAP SEM In The Classroom}

With the economy and stock market on the rise, firms are beginning to have excess money; thus, thousands of companies have been increasing their investments in technology. In the new millennium, "integration" and overall efficiency are two of the business world's newest concepts. ERP software has been able to develop hand-in- 
hand with these new phenomena. Fortune magazine recently rated enterprise computing as one of the top technologies to watch and predicted a 35 percent growth per year over the next three years.

Controlling over 50 percent of the market share, SAP is broadly recognized to be the market leader and four times larger than their closest competitor. Saint Joseph's University's mission is to offer degree programs that stress the development of the knowledge, skills, abilities, and values that prepare graduates to assume leadership roles in organizations of all sizes and types. In accordance with the University mission statement, it would seem rational for the Accounting Department to implement the premier ERP package into the curriculum. The objective in this is to offer students exposure to the most "cutting-edge" technology and its capabilities.

The SAP University Alliance Program for the United States, Canada, Central and South America builds upon the best components of such a program originally developed for European institutions of higher education. It has been developed by SAP America to facilitate the use of their software package (and integrated business solutions concepts) in the formal education of undergraduate and graduate students throughout the Americas. The program has grown from a charter of five members in 1997 to over 124 member institutions as of March 2003. The Haub School of Business is proud to be among the early schools granted admission in 1998.

Upon admission to the SAP America University Alliance Program, new members receive four significant and valuable items. First, a fully functional copy of the SAP SEM software (or time-share rights with a major service provider is acquired). Second, they receive copies of all professional training materials used by SAP. Third, one hundred days of free training for faculty members at SAP professional training classes. The amount of training is dependent upon the level of involvement that a member institution desires. Fourth, they are given access to technical support from SAP. In addition, SAP is actively working with its member institutions to ensure cooperation and sharing of course materials among member institutions.

There are several things that separate SAP SEM from its competitors. The ability to be a fully-integrated package, with real-time applications, is the most unique of them all. No other software package has the ability to be as fully integrated as SAP. When information is entered in one module, or one department, the same information is reflected throughout the system. SAP SEM offers give main applications and associated tools:

- Business Planning and Simulation (BPS), which integrates strategic and operational planning, with modeling, simulation and scenario planning facilities. Activity-based management is used to add a process view to the functional view of an organization, which is reflected in resource planning.

- Business Consolidation (BCS) for financial reporting internally and externally, including value-based accounting.

- $\quad$ Corporate Performance Monitoring (CPM), providing support for the definition, analysis, visualization and interpretation of key performance indicators, both, financial and non-financial, internal and external. The Balanced Scorecard (Kaplan and Norton, 1992) is a key tool here, together with associated chains of cause and effect among multiple performance dimensions (Kaplan and Norton, 1996 and 1997) useful during the planning process.

- $\quad$ Business Information Collection (BIC), which collects structured and unstructured business information from internal and external sources.

- $\quad$ Stakeholder Relationship Management (SRM), which supports the stakeholder communication process.

This paper explains and demonstrates one component of SEM. That component is Performance Corporate Monitoring, which mapped into the Management Accounting Information Systems II course.

\section{What Is PC4YOU?}

PC4YOU (the simulated company used to demonstrate SEM) is an example of a typical customer solution offered by SAP. The students are pointed out that PC4YOU is a fully integrated company. It designs, develops, manufactures, markets, sells and supports a wide range of hardware and software products that can be customized to customer requirements. Its two primary product categories are: desktop computer systems and software products. As 
a part of the hardware segment, PC4YOU offers a wide range of peripherals, including printers and projectors. As a part of their software segment, PC4YOU sells a wide range of third-party software products, including business and office applications and anti-virus and related security software.

As a response to new market opportunities, the company has begun a strategic re-orientation of its core business that is supporting customers with the highest quality hardware and software products. The unique position of PC4YOU lay on the fact that it is able to offer the customer fully tested, user friendly and adaptable hardware and software.

After the year 2002, PC4YOU moved the entire company to Munich, Germany and, therefore, the reporting currency is Euro. At a general meeting of shareholders in January 2006, a successful re-organization occurred and a change in strategy was introduced with the aim of positioning PC4YOU as a major management and technology software provider. PC4YOU adopted a set of measures in order to validate that this re-structuring was successful. With this thumbnail background, students are able to gain some understanding that performance measures take place against a larger strategic background. At the same time of the re-organization, a sense of the corporate board was the need to garner real economic returns from the implementation of SAP done some years earlier. The task of the student teams is to attempt to get some sense of performance value and efficiencies garnered from the effective use and analysis of SEM.

\section{What Are The Key Performance Indicators (KPI)?}

As the simulation begins, students are led in a discussion regarding the concept of shareholder value. They are presented with a video explaining that pressure from investors to deliver sustained, superior returns was making shareholder value enhancement an issue for the corporation. Many large institutional investors have begun to actively invest in PC4YOU. With this new shareholder group, the days of passive shareholders and reactive management decisions without accountability to investors are over. The following key questions were raised at the recent shareholders' meeting:

- $\quad$ How can we accelerate profitable growth over the next several years?

- What really drives value in our business?

- $\quad$ How can we promote a culture of value creation throughout the company using modern day technology tools?

\section{What Is The Balanced Scorecard (BSC) And How Is It Incorporated Into The Course?}

An integral part of implementation of SEM within PC4YOU is the ability to define performance measures in concrete, measurable terms. The executive committee of the board felt strongly that the Balanced Scorecard (referred to in this paper as: BSC) was the best place to start. Students are now presented with a series of readings on the BSC concept as developed by Robert Kaplan and David Norton. These articles are cited in the bibliography of this paper.

Under the BSC approach within SEM, top management is able to translate its strategy into objectives that employees can understand and use to take action. These objectives, utilizing the BSC, tend to fall into four perspectives: Financial, Customer, Internal, and Learning and Growth. Furthermore, once an objective has been assigned to one of the four perspectives it becomes necessary to define accurate measures for that objective, target goals must be established, and an initiative must be undertaken in order to ultimately achieve the desired objective as shown in the following diagram. 


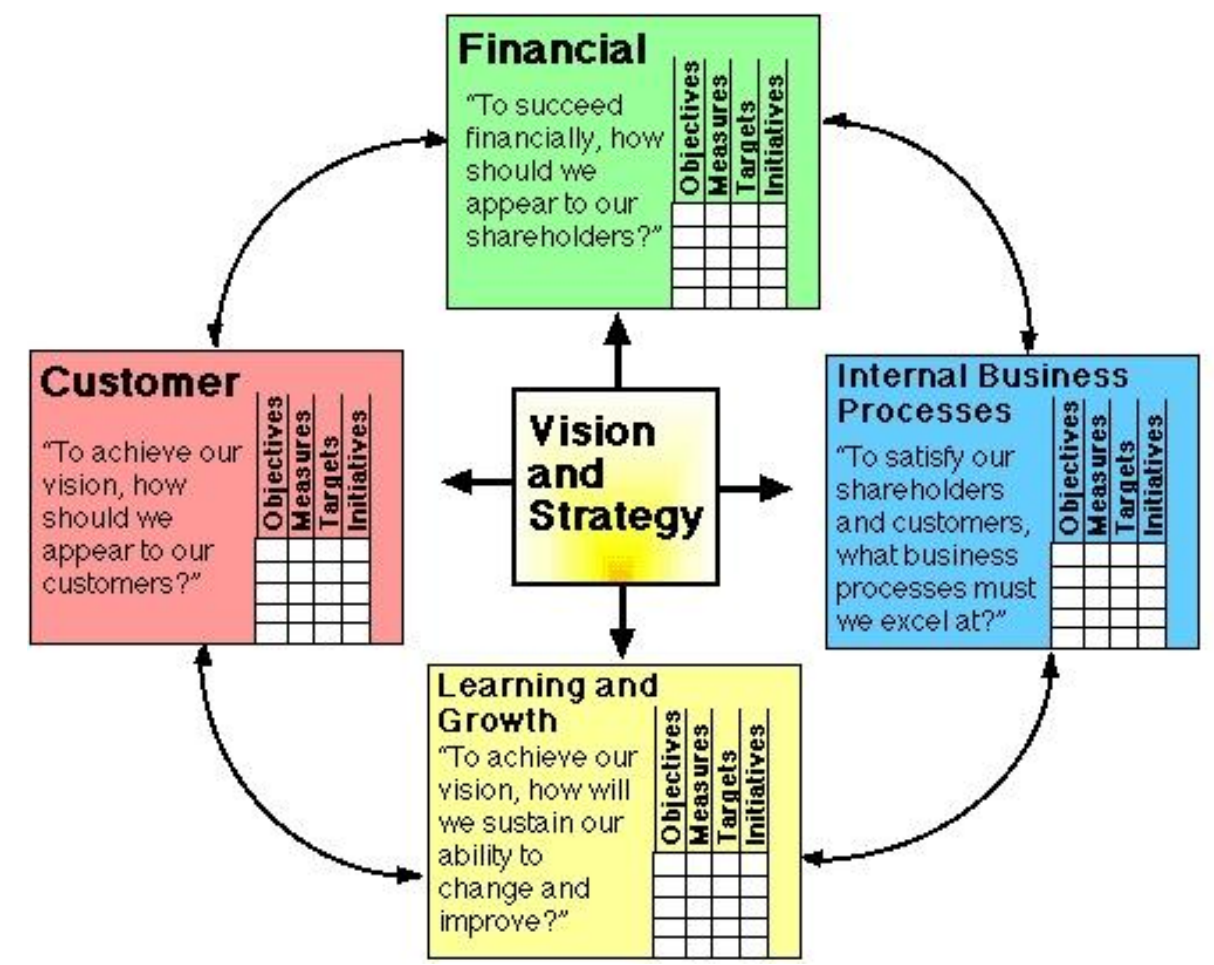

Source: www.balancedscorecard.org/basics/bsc1.html (Paul Arveson, 1998)

Students are now asked to put themselves in the position of the PC4YOU Board of Directors and determine how each of these perspectives should be measured and what initiatives should be undertaken. They are advised that the BSC should consist of controllable variables managers can personally influence that relate to performance measures that will directly affect strategy and vision. In addition, students are asked where performance measures should be linked together on a cause and effect basis. Each link can then be read as hypothesis in the form, "if we reduce time to market (an internal perspective), we will increase revenue and, therefore, increase shareholder value (a financial perspective). Another hypothesis would be if the company hires talented people (a learning and growth perspective), better products will emerge, which will reduce customer complaints (a customer perspective). The key here is to get the students to see as many links as possible within the BSC that they are creating for PC4YOU. After much discussion, the executive committee of the board is able to create the necessary objectives, measures, and initiatives in each category as described below.

\section{Financial Perspective}

PC4YOU's financial perspective involves many different desired objectives. Ultimately it will be proven that the objectives of the other four PC4YOU BSC objectives will affect the objectives Financial Perspective. Below is an example of a few of PC4YOU's financial objectives and the measures and initiatives PC4YOU uses to define the objective performance. (Note: PC4YOU has not defined any initiatives for the objectives of the Financial Perspective because top management believes that the objectives of the other three BSC perspectives are ultimately the drivers for the financial perspectives.) 


\begin{tabular}{|l|l|l|}
\hline \multicolumn{1}{|c|}{ Objective } & \multicolumn{1}{c|}{ Measure } & \multicolumn{1}{c|}{ Initiative } \\
\hline Increase Shareholder Value & $\begin{array}{l}\text { Economic value added } \\
\text { Discounted cash flow } \\
\text { Total shareholder return }(1 \mathrm{yr})\end{array}$ & $\begin{array}{l}\text { Driven by the objectives of the three other } \\
\text { perspectives }\end{array}$ \\
\hline Become a market share leader & Market rank & $\begin{array}{l}\text { Driven by the objectives of the three other } \\
\text { perspectives }\end{array}$ \\
\hline $\begin{array}{l}\text { Grow revenue from wholesale } \\
\text { customers }\end{array}$ & Relative market share & $\begin{array}{l}\text { Driven by the objectives of the three other } \\
\text { perspectives }\end{array}$ \\
\hline
\end{tabular}

This only gives a snapshot of the objectives within the corporation, for it would not be necessary to explicate the linkage between all of the objectives because the overall capability of the BSC can be demonstrated on a smaller scope.

\section{Customer Perspective}

PC4YOU's customer perspective identifies the key objectives around customer and market segments in which the company can successfully compete. These segments help deliver the revenue component of our company's financial objectives, which act as a critical measure of performance. The customer perspective enables our company to align our core customer outcome measures - satisfaction, loyalty, retention, acquisition, and profitability - thus targeting customers and segments. As planned objectives, it also enables us to identify and measure the initiative that we will deliver to targeted customers and market segments. An example of some objectives, measures, and initiatives can be found within PC4YOU's BSC can be found below.

\begin{tabular}{|l|l|l|}
\hline \multicolumn{1}{|c|}{ Objective } & \multicolumn{1}{c|}{ Measure } & \multicolumn{1}{c|}{ Initiative } \\
\hline $\begin{array}{l}\text { Offer latest technology at a premium } \\
\text { price }\end{array}$ & Price Premium vs. Competition & Review and modify pricing scheme \\
\hline Create image as a top innovator & Survey result: Customers agreeing & $\begin{array}{l}\text { Support Innovation Contest } \\
\text { Innovation Ad campaign }\end{array}$ \\
\hline Reduce quality complaints & No. of quality complaints & $\begin{array}{l}\text { Six Sigma initiative in quality } \\
\text { management }\end{array}$ \\
\hline
\end{tabular}

\section{Internal Perspective}

PC4YOU's internal perspective identifies the internal processes as key objectives most critical for achieving customer and shareholder satisfaction. The objectives and measures in this perspective have been developed after formulating objectives and measures for the financial and customer perspectives. This sequence enables us to focus our internal-business-process metrics on those processes that will deliver the objectives established for customers and shareholders. An example of some objectives, measures, and initiatives can be found within PC4YOU's BSC can be found below.

\begin{tabular}{|l|l|l|}
\hline \multicolumn{1}{|c|}{ Objective } & \multicolumn{1}{|c|}{ Measure } & \multicolumn{1}{c|}{ Initiative } \\
\hline Improve R\&D Process & Average duration of an R\&D project \\
No. of parallel R\&D projects & $\begin{array}{l}\text { Establish patent department } \\
\text { Review and modify corporate R\&D } \\
\text { policies. }\end{array}$ \\
\hline Improve patent process & $\begin{array}{l}\text { No. of new patents } \\
\text { Time to patent approval }\end{array}$ & Establish patent department \\
\hline Reduce time to market & Average development time per product & Bureaucracy reduction program \\
\hline
\end{tabular}




\section{Learning And Growth Perspective}

PC4YOU's learning \& growth perspective develops objectives and measures to provide the infrastructure to enable objectives in the first three scorecard perspectives to be achieved. These objectives are mainly concerned with employee capabilities, information systems capabilities, and motivation, empowerment, and alignment. An example of some objectives, measures, and initiatives can be found within PC4YOU's BSC can be found below.

\begin{tabular}{|l|l|l|}
\hline \multicolumn{1}{|c|}{ Objective } & \multicolumn{1}{|c|}{ Measure } & \multicolumn{1}{c|}{ Initiative } \\
\hline Hire talented people & Percent of employees with degrees & $\begin{array}{l}\text { Implement a strategic hiring } \\
\text { campaign }\end{array}$ \\
\hline Align organization to strategy & $\begin{array}{l}\text { Percent of employees owning BSC } \\
\text { element }\end{array}$ & $\begin{array}{l}\text { BSC rollout program } \\
\text { Create a strategic sales training } \\
\text { program }\end{array}$ \\
\hline Improve technology infrastructure & $\begin{array}{l}\text { Down time of mission critical systems } \\
\text { Percentage of completion CRM project }\end{array}$ & $\begin{array}{l}\text { SAP information Warehouse } \\
\text { implementation }\end{array}$ \\
\hline
\end{tabular}

\section{What Initiatives Should Be Undertaken To Maximize These Measurements?}

Using classroom discussions, students were asked to define the key initiatives and measurements (if necessary) that would enable the achievement of targeted goals and objectives chosen previously. Some of these initiatives presented in the first iteration were as follows:

\section{Review And Modify Pricing Scheme}

- $\quad$ The pricing scheme that is currently in place needs improvement to react flexibly to the expected high volume shipments in the reseller area. Product and partner related discount schemes will be worked out and implemented. This includes the creation of a training program for our sales team.

\section{Support Innovation Contest}

- $\quad$ The innovation contest that is owned by the group will help to create a competitive atmosphere in the R\&D teams. The result of this project should be the implementation of an innovation award that will be awarded annually for successful reduction of the R\&D cycle time.

\section{Innovation Ad campaign}

- $\quad$ Based on the ad campaign from the group, that will focus on three major areas:

1. Image as innovator

2. Leadership in Quality

3. Good corporate citizen

\section{Six Sigma Initiatives In Quality Management}

- A six sigma project will be launched to improve our quality management. The ultimate goal will not necessarily be to reach the statistical 3.4 defects per million opportunities, which is what six sigma stands for, but to optimize all quality management processes to detect and avoid product flaws that would later increase our cost of non-quality. The main part of the project will be to work out a teaching program for our QM employees. 


\section{Establish Patent Department}

- $\quad$ The, to be formed, patent department will support our goal to improve the R\&D process as such. We will have to find a suitable location, budget, and some external consultancy to help us successfully complete the start up phase. The project does not include the staffing of the patent department and the search for an adequate manager. This will be managed in a different project.

\section{Review And Modify As Necessary, Corporate R\&D Policies}

- $\quad$ Put together a task force to identify weak points of the current R\&D policy and to suggest and implement improvements to the current process. This also includes the selection of new software tools to evaluate product time to market.

\section{Bureaucracy Reduction Program}

- $\quad$ The bureaucracy reduction project will search through all existing written company policies and evaluate if they are still necessary under a checks and balance view. Those that can be skipped will be presented to the board, which will finally decide what to do about those policies.

\section{Implement A Strategic Hiring Campaign}

- $\quad$ A revised hiring campaign and program is required to ensure that a new breed of employee is hired based on the strategic objectives of the corporation.

\section{BSC Roll-Out Project}

- $\quad$ Roll out of the Balanced Scorecard Methodology and Software to all major business units. This will include a reengineering of the reporting and controlling processes we relied on so far and will help enable each product segment to evaluate better information and become more efficient in responding to it.

\section{Create a Strategic Sales Training Program}

- $\quad$ Create and deliver a sales training program that identifies the latest in selling techniques in which we hire sales people with college degrees.

\section{SAP Information Warehouse Implementation}

- $\quad$ The SAP BW application will help the overall corporation to standardize reporting across platforms and provide us access to the very latest product offerings made by SAP. 


\section{What Does PC4YOU Look Like From A Financial Point-Of-View?}

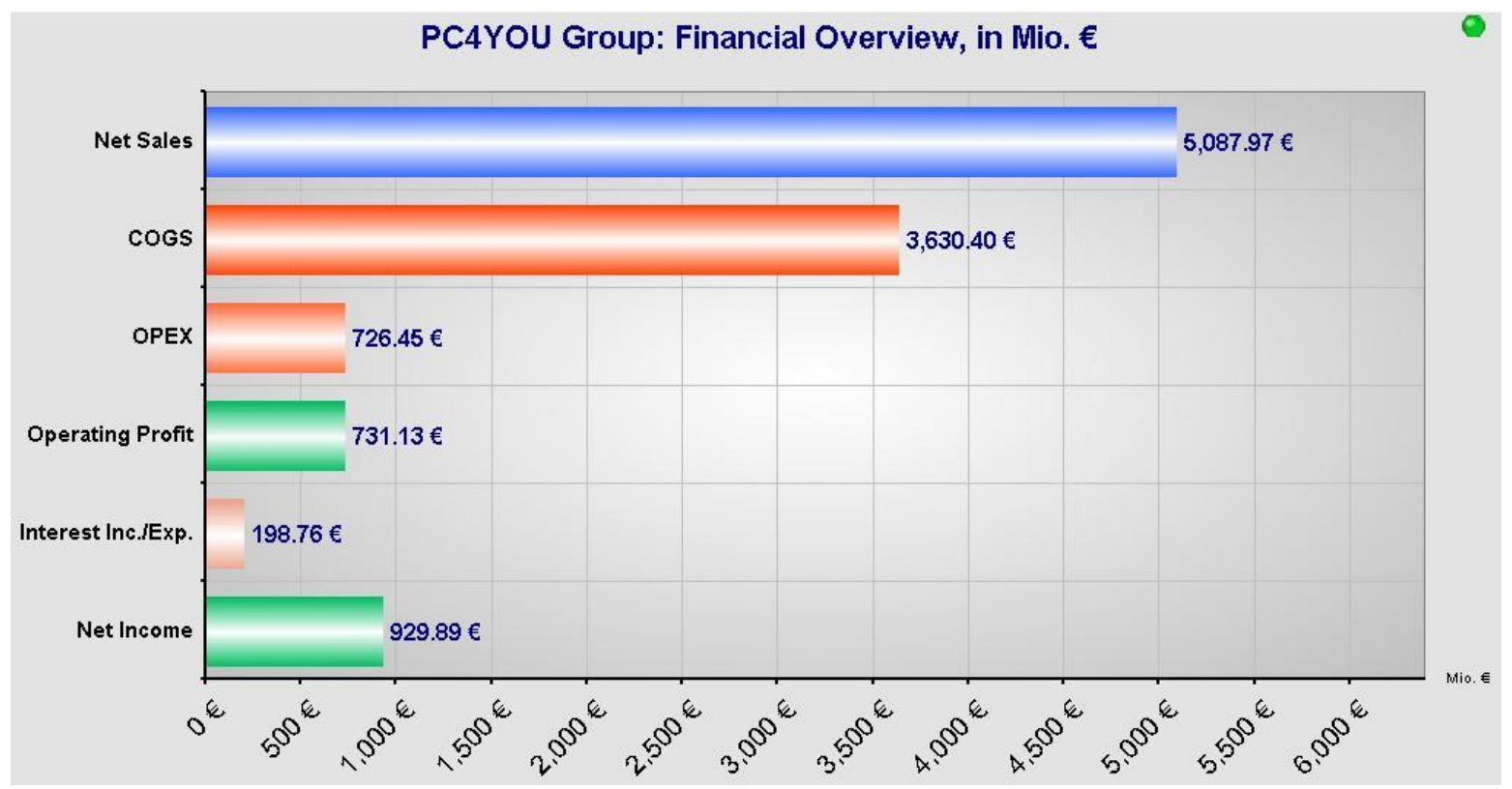

By using the Management Cockpit (t-code: umm_pres) in the first half of 2006, the Net Sales of our company was $€ 5,087$. After taking into account our Cost of Goods Sold and Operating Expense, our company's Operating Profit was $€ 731$. Finally, PC4YOU earned $€ 198$ in Interest Income, which brought our Net Income for the first half of 2006 to $€ 929$. These are targets that were planned for by student groups in the early part of April and have obviously been successfully achieved as of July 2006. The Euro is used due to the fact that PC4YOU relocated to Munich, Germany in 2002.

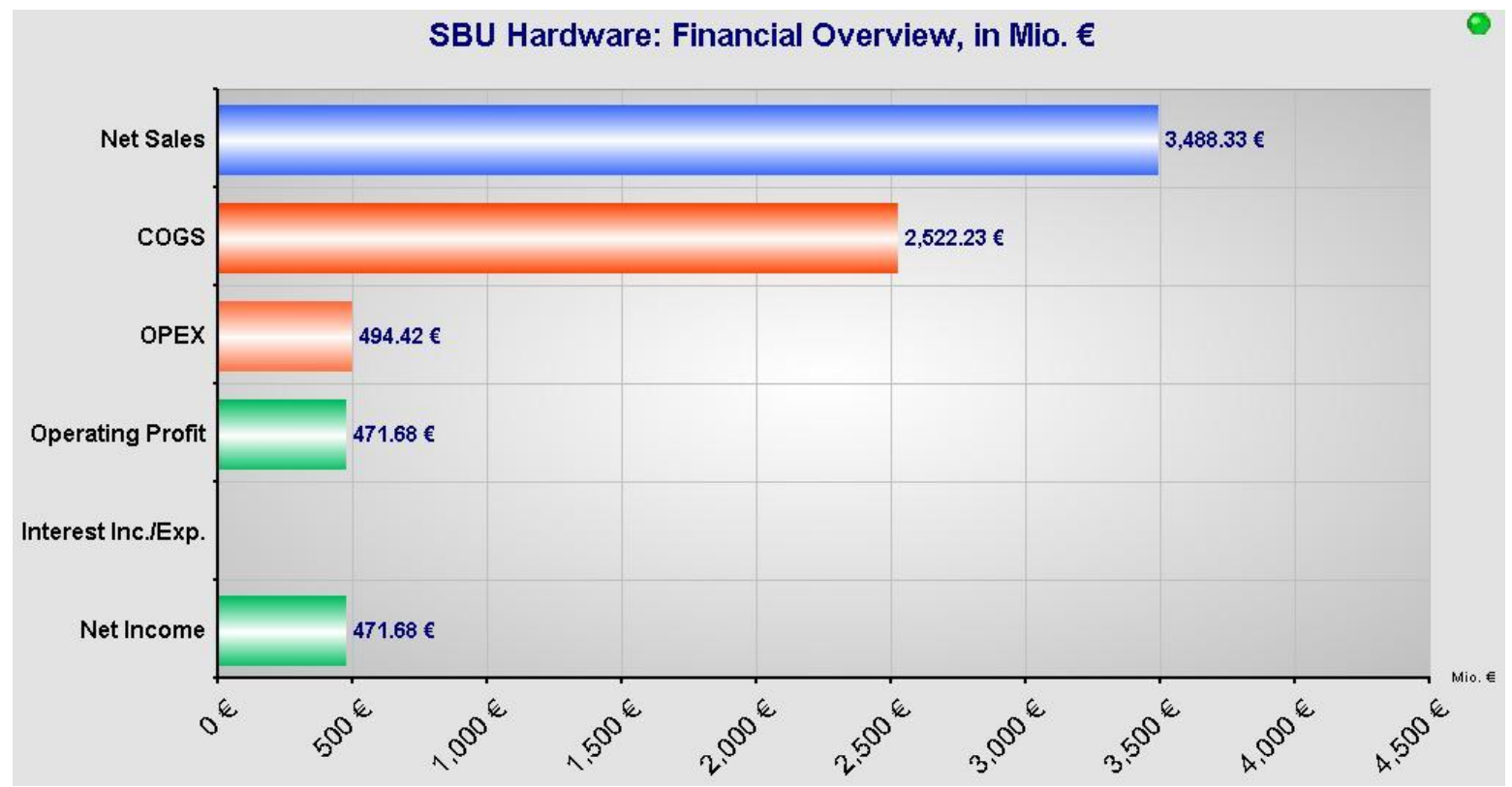


Since our company has multiple products, the next obvious step is to break out the product segments to see which is larger and more profitable. By using the Management Cockpit (t-code: umm_pres) in the first half of 2006, the Net Sales for the Hardware division were $€ 3,488$ (as noted above). After taking into account our Cost of Goods Sold and Operating Expense, the company's Operating Profit was €471. This number then dropped down to the bottom line, representing Hardware Net Income at $€ 471$

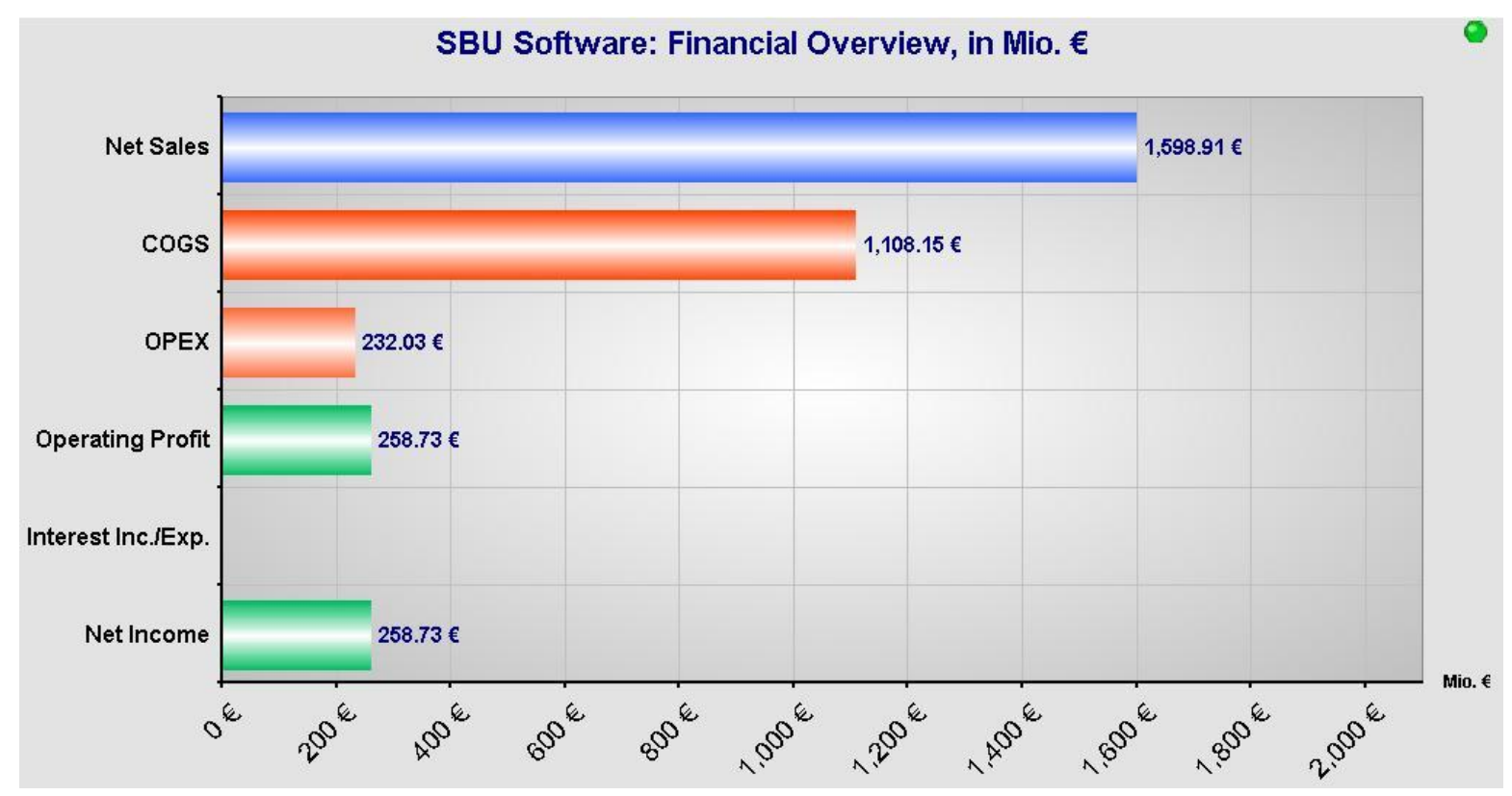

Our company's second product segment is its Software division. By using the Management Cockpit (tcode: umm_pres) in the first half of 2006, the Net Sales for the Software division were $€ 1,598$ (as noted above). After taking into account our Cost of Goods Sold and Operating Expense, the company's Operating Profit was $€ 258$. This number then dropped down to the bottom line, representing Software Net Income at $€ 258$.

It is interesting to note that Other Income, represented as 198 in the Group Financial Overview is not represented on either of the segment overviews. This is because of current accounting rules, in which umbrella income and expense items are kept at the corporate level. Students are quick to note that the interest percentage of hardware $(13.5 \%)$ is much less than software $(16.1 \%)$. This enables the first point of analysis, namely that the product with the larger amount of revenue is generating a smaller percentage of profit. Let's see if other financial measures attest to this. 


\section{What Other Factors Are Measured By Financial Perspective?}

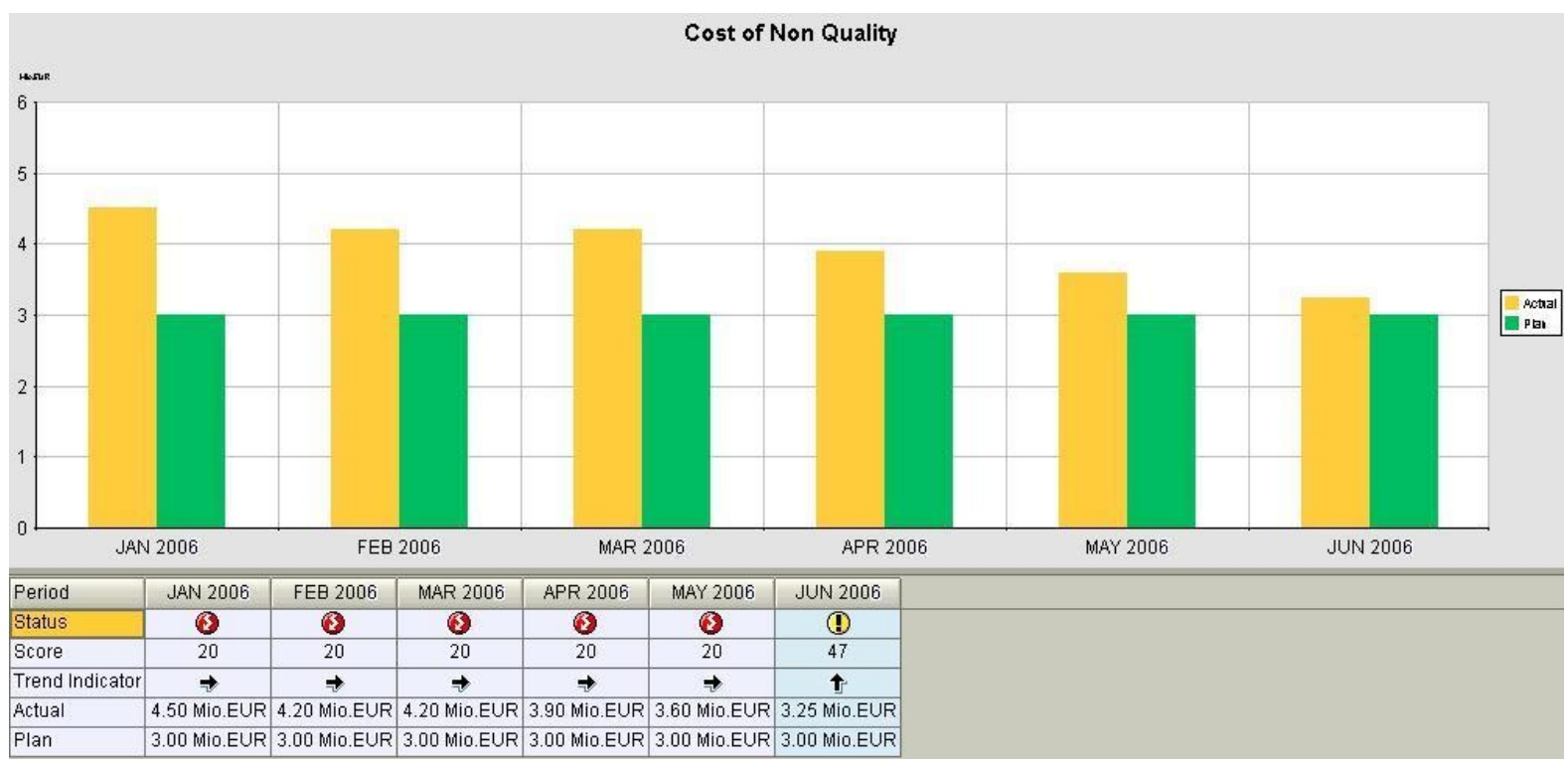

Classroom discussion regarding financial measures of performance often raises the obvious measures derived from an income statement. The common issues always seem to be: increase revenue and increase profit. Broadening the discussion to include the components that drive income is particularly important in accounting education. Within this simulation and as an integral part of internal process, students are able to identify quality management as a major factor in the cost of production and delivery of computer hardware and software. Students then become motivated to track this cost as an integral part of the financial performance of the company. The graph on the previous page demonstrates a BSC perspective within SEM. This breaks out six months and shows actual verses plan with a trend indicator, a score and current status. These numbers are compared to plan, which is three million euros. A variance analysis of the data in January 2006 shows a low score because actual (4.5 million) exceeds plan (3.0 million). This gives a low score and a red status marker indicating concern. As we move to June 2006, the actual (3.25 million) exceeds plan by a smaller amount. The achievement score has gone to 47, a positive trend is noted and status has gone to merely cautionary. Graphical analysis is also represented here for the six month period. The Management Cockpit (t-code: umm_pres) simply shows a gauge for June 2006 reflecting actual Hardware Cost of non-quality being slightly higher than plan. With this as a baseline, students in future months will be able to compare performance and watch the gauge and graphs as they change. 


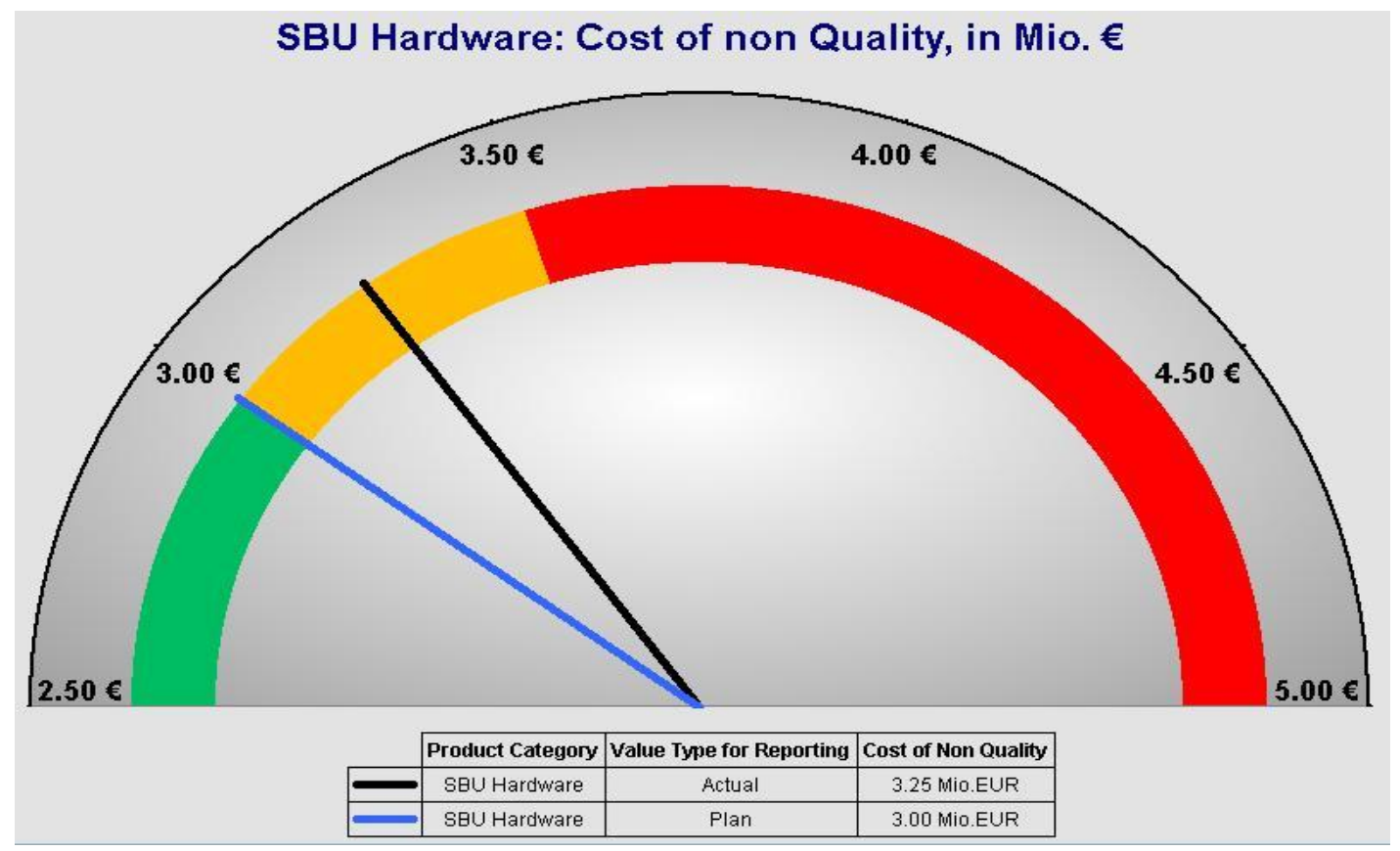

\section{Are The Balanced Scorecard Measures Linked?}

Within the classroom discussion that takes place prior to the start of simulation, much time is spent in showing the interrelated linkages between the components of the BSC. In a simple analysis of PC4YOU, the overall corporate goal is to become number one in the PC industry. In order to ensure that financial objective, customer, process and growth perspectives must correctly align. In order to achieve profitability, one has to attract customers. A goal defined by the class is to achieve the best price performance ratio. In order to achieve the best price performance ratio, one must successfully achieve time to market, which means speeding up research and development processes. From the learning and growth perspective, none of this is possible without the hiring and retention of a high quality professional staff. The graph below indicates the relationships defined by students. Although, somewhat singular, these relationships provide them a skill and ability in later cap-stone courses, like our Senior-level Business Policy course, where multiple variance analysis is required.

\section{Learning And Growth Perspective}

In order to achieve corporate objectives, a number of resources must coincide to effectively produce the desired outcome. Learning and growth aspect of the BSC focuses on a few the human resources side and a key measure (marker) is percentage of employees with advanced degrees. This is particularly true in the information technology industry. A review of the BSC (t-code: umb_pres) for percent of employees with advanced degrees shows the following gauge: 


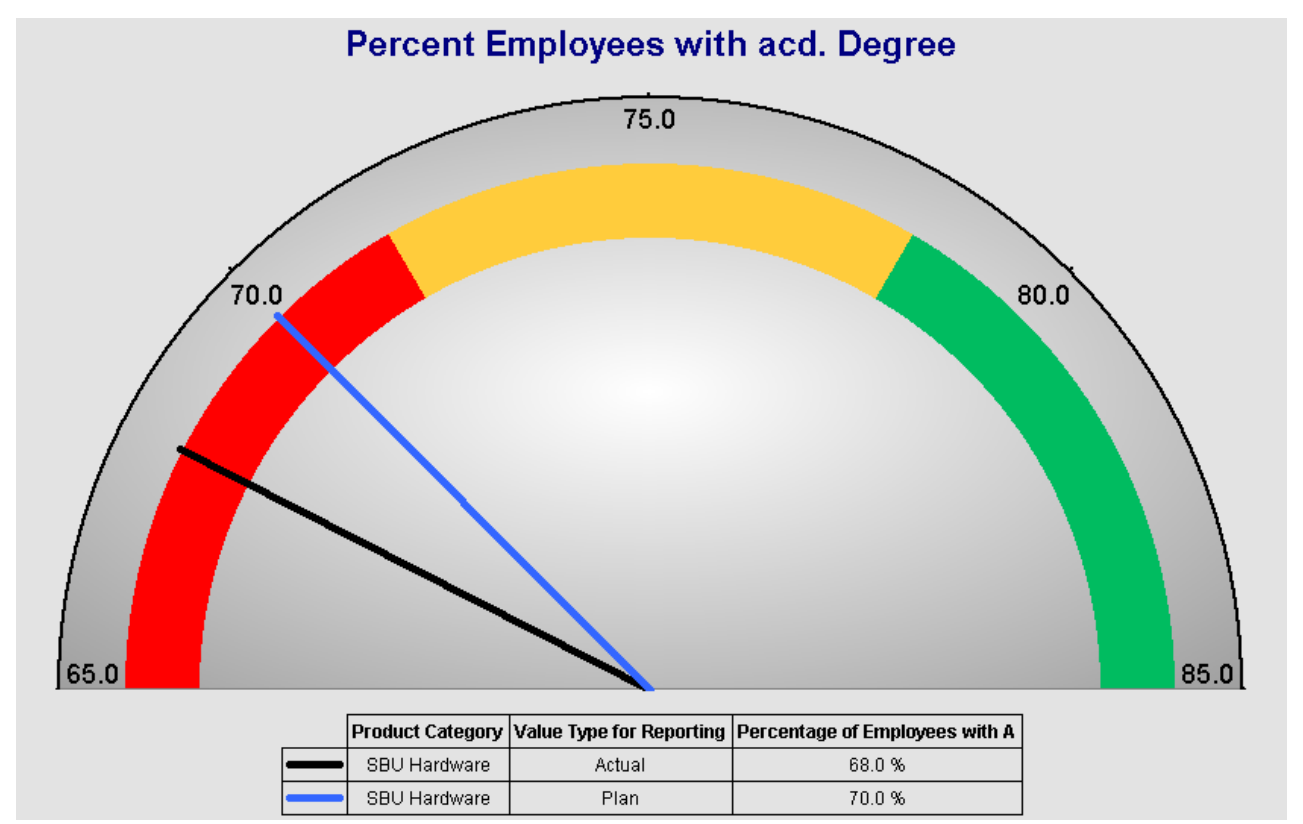

The BSC objective "Hire talented people" is assessed by the number of employees with advanced degrees. PC4You would like to achieve a planned percentage of $70 \%$. As shown in the diagram, the actual percentage for the period was $68 \%$. As an unfavorable marker, this may impact the growth of new products and the cycle time of delivery of product to the market place. In and of itself, it is close enough to target not to raise concern. The real question is what impact will it have on other markers?

\section{Internal Business Perspective}

In order to achieve corporate objectives, a number of resources must coincide to effectively produce the desired outcome. We will consider the affect that the "Hiring talented people" objective has on other BSC measures as PC4You attempts to reach its ultimate goal of becoming a market leader. Internal Business Perspective focuses on a few key BSC objectives: "Improve R\&D process," "Improve patent process," and "Reduce time to market." A key measure (marker) to consider within the "Reduce time to market" objective is the average development time of products measured in days (as seen in the diagram below). This is particularly true in the information technology industry. A review of the BSC (t-code: umb_pres) for percent of employees with advanced degrees shows the following gauge: 


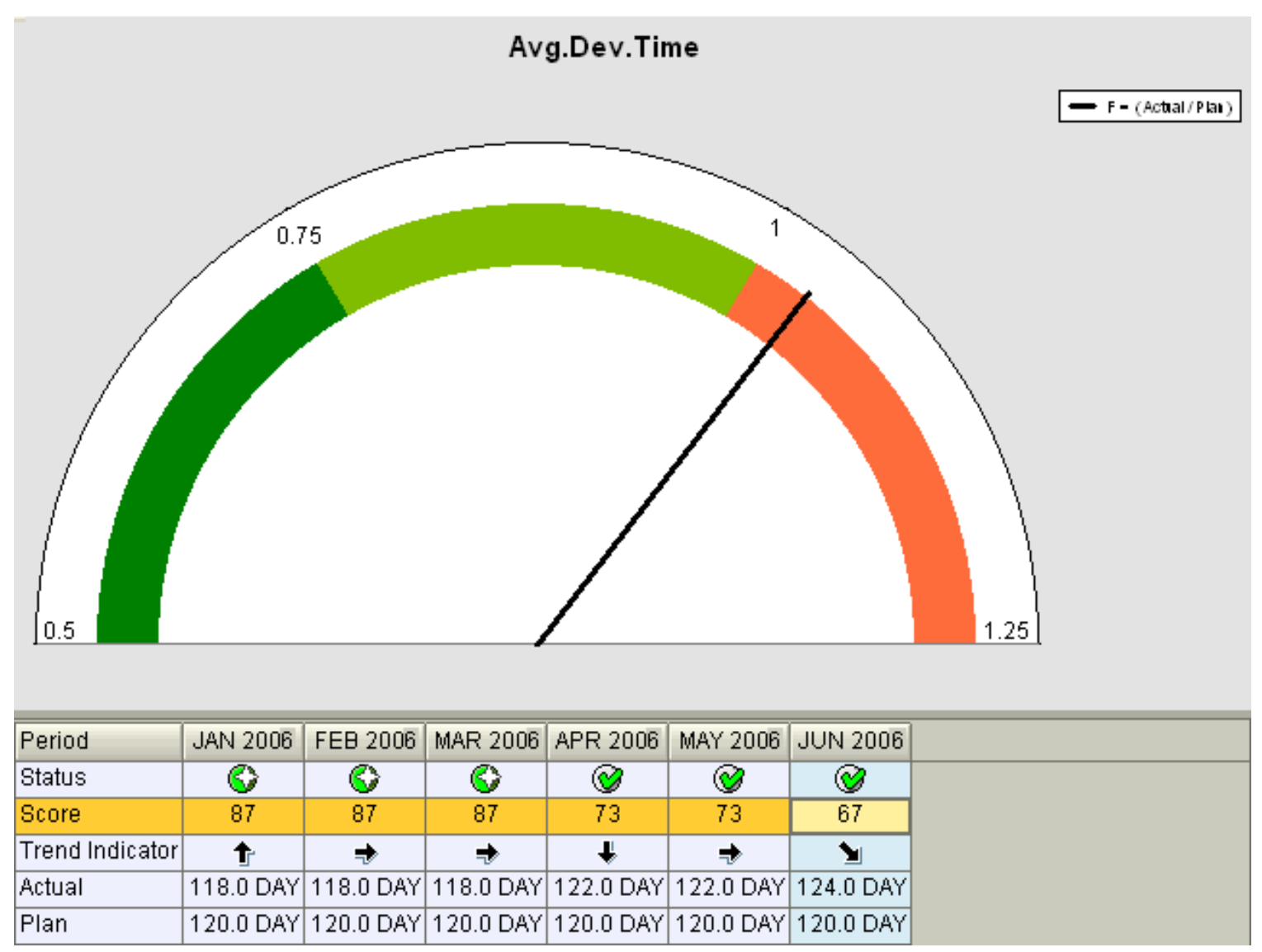

This gauge shows that the average development time of their products is 124 days in June when PC4YOU had a target of 120 days. The measure shown in the gauge is the ratio of actual to planned days in development, which imply the desire for a ratio of less than 1 . In this case, the ratio is greater than 1 (1.033) and in the red zone (graphical indicator), therefore, it reflects the current problem with the objective "Hire talented people." To make the connection, if the objective to "Hire talented people" is not reached, it will in turn affect the BSC Internal Perspective of "Improve R\&D process" under the assumption that a more educated work force would be able to streamline and improve this process. Furthermore, because the improvement of the R\&D process is a triggering objective for two other Internal Perspectives, "Improve patent process" and "Reduce time to market," it will cause a negative chain reaction that will work its way even further toward PC4YOU's ultimate goal. This shockwave effect is demonstrated by the above diagram.

\section{Customer Perspective}

In order to achieve corporate objectives, a number of resources must coincide to effectively produce the desired outcome. We will further consider the shockwave effect of the BSC by looking at the Customer Perspective. Customer Perspective focuses on a few key BSC objectives: "Offer latest technology at a premium price" and "Create image as a top innovator." A key measure (marker) to consider within the "Offer technology at a premium price" objective is PC4YOU's price premium vs. competition (as shown in the diagram below). A review of the BSC (t-code: umb_pres) for Price Prem.vs.Comp. shows the following gauge: 


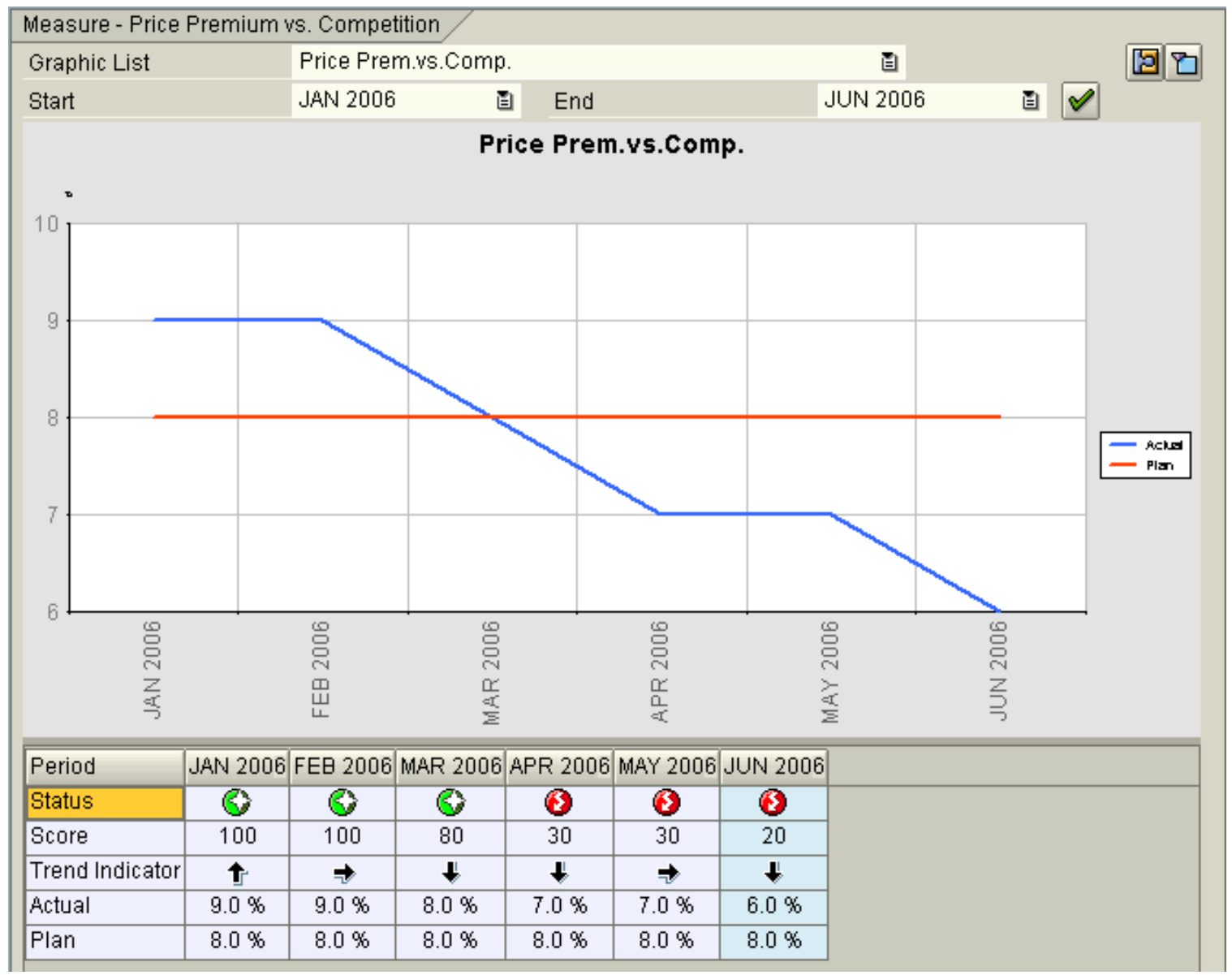

The following conversation was taken directly from SAP's SEM system within the BSC in reference to the above objective (See appendix B).

Assessment:

"The situation this month needs some explanation. First of all, our customer survey show, that a majority of our customers rates us as a very innovative company, that is able to deliver a significantly higher level of quality and advanced technology than our competitors. On the other hand, the same customers indicate, that our list prices are by far exceeding what they are willing to pay as a premium to obtain that value proposition. So I strongly believe, we have to stress how beneficial it is for our customers to rely on the latest technology, and that the TCO in the long run will even be lower, when buying our products than if turning to low cost offers from the competitors. Therefore we should gather a task force that first does a couple of example calculations on TCO to show how well the customers invest their money and second finds suitable means to communicate this message to the market."

\section{Agree:}

"I have to agree with what John said. Unfortunately June was the 6th consecutive month where the price premium was declining. We should as soon as possible start activities to overcome this unpleasant situation." 
Watch Out:

"As Mentioned in the assessment for the EVA, the situation is not as good as it seems. The market does not reward our superior technology and quality in the way we expected and we have to grant rebates that are too high."

The above gauge shows that PC4YOU's price premium has declined steadily over the past six months. It also shows that PC4YOU has fallen below its target of $8 \%$ and is now at $6 \%$. Therefore, to further explicate the relation the other measures have had on this objective, it is important to look at the triggering objectives. For "Offer latest technology at a premium price" there are two triggering objectives: "Improve patent process," and "Reduce time to market." As stated in the Internal Perspective, because the objective to "Hire talented people" has not been achieved, it has caused a shockwave, of which the effects are felt in the Customer Perspective as shown above. Also, within the Customer Perspective, the triggering objective for "Create image as a top innovator" is the aforementioned "Offer latest technology at a premium price," therefore, in speculation; the shockwave has further extended its damage.

It should also be noted that below the diagram there is a management conversation being held in the assessment section of this particular objective. In this particular conversation management notes that the decline has been steady for 6 months straight, but furthermore, they also note that product quality, innovation, and technological advances has not paid off due to the price premium they are charging. This may be because all of the other perspectives viewed in the BSC have not met their targets, therefore, new initiatives may need to be considered by the students.

\section{Financial Perspective}

\section{Market Rank}

In order to achieve corporate objectives, a number of resources must coincide to effectively produce the desired outcome. We will finally consider the culmination of the shockwave effect of the BSC by looking at the Financial Perspective. The Financial Perspective focuses on a few key BSC objectives; the one stressed here is "In each market become at least \# 2." A key measure (marker) to consider within the "In each market become at least \# 2" objective is PC4YOU's Market Rank (as shown in the diagram below). A review of the BSC (t-code: umb_pres) Market Rank shows the following gauge:

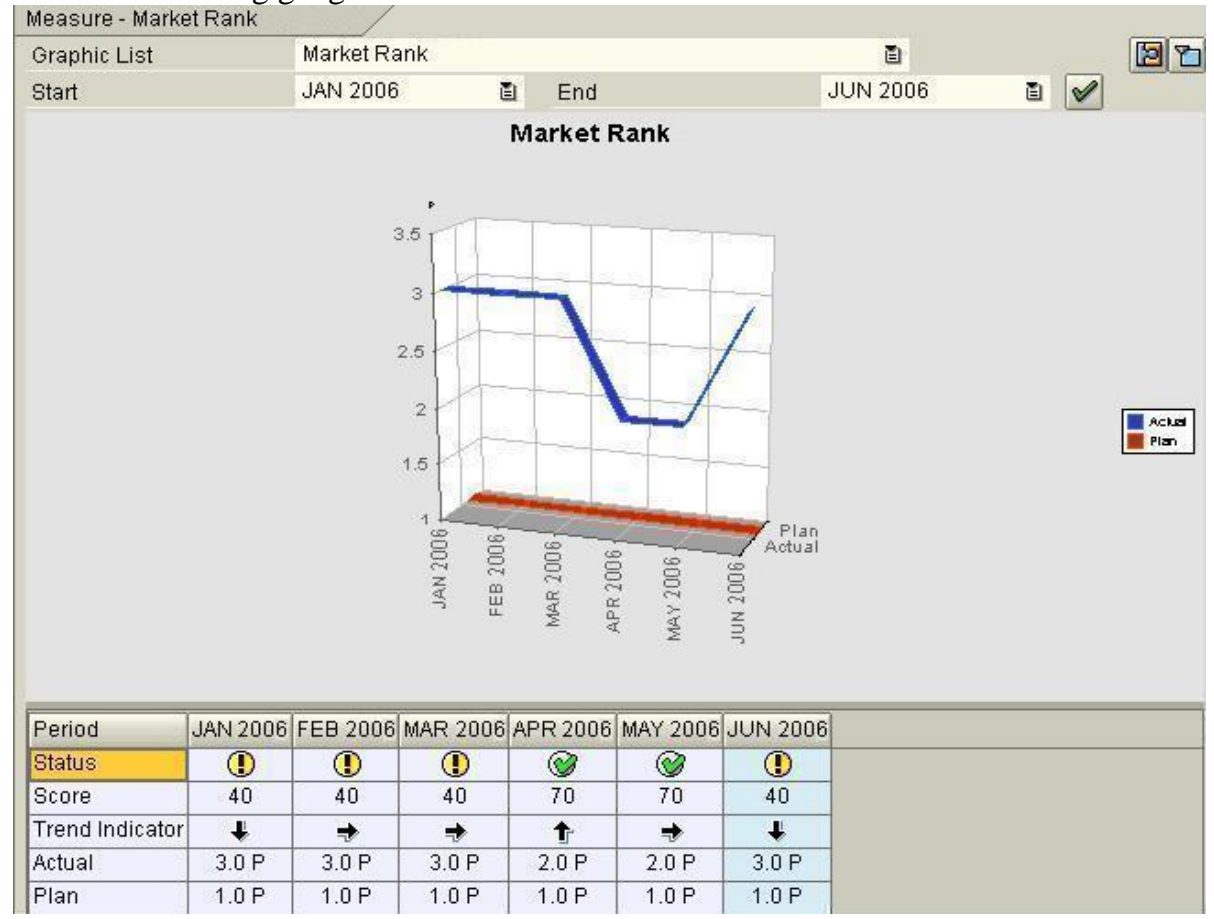


This graph shows that PC4YOU's market rank has declined over the past two months. Starting in mid March, as shown by the graph, PC4YOU raised its ranking (dropped in the graph) to number 2 in the market. Since then, however, their market rank has dropped (risen in the graph) to the number 3 position when, ultimately, PC4YOU would has a planned goal of being number 1 . Therefore, to further explicate the relation the other perspectives have had on this objective, it is important to look at the triggering objectives. For "In each market become at least \# 2" there are two triggering objectives: "Create image as a top innovator" and "Offer latest technology at a premium price." As stated in the Customer Perspective, because the objective to "Hire talented people" has not been achieved, it has caused a shockwave, of which the effects are felt in the Financial Perspective as shown above. The students should reflect on the impact that such objectives, when looked at alone, may not seem to be that significant, but when looked at using powerful software such as the SEM system within SAP it enables management to see the connections a certain objective or decision may have on the whole corporation.

\section{Economic Value Added (EVA)}

To further link the Learning and Growth, Internal, and Customer perspectives of the BSC with the Financial Perspective, Economic Value Added, a measure within the "Increase Shareholder Value" objective, shall be considered. A review of the BSC (t-code: umb_pres) Market Rank shows the following gauge and related management assessment:

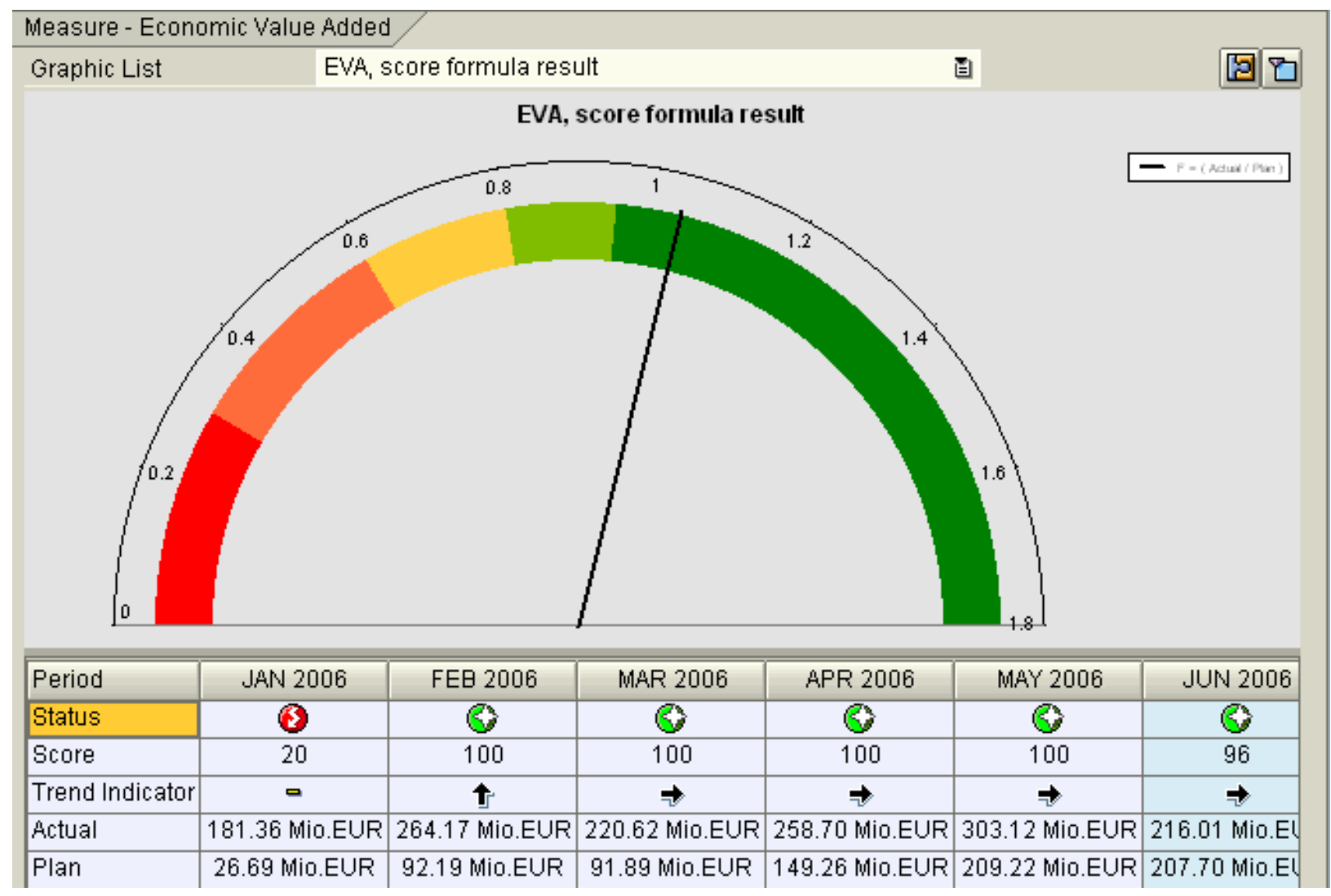

The following conversation was taken directly from SAP's SEM system within the BSC in reference to the above objective (See appendix C). 
Assessment:

"The Situation this month needs some explanation, as the sheer numbers will not reveal the real situation. The reasons for that are manifold and among those are: First: We had a much better than expected first half year, what cannot be expected for the second half as well. Therefore the annualized numbers will not stay that good in the next six month. Second: Some KPIs regarding market share and the price premium we earn for our superior technology are not that satisfying. Take a look at the KPI "Price Premium vs. Competition" in the Customer Perspective and decide for yourself."

\section{Price Premium:}

"John is right in his analysis regarding the negative trend of the Price Premium vs. Competition.

The market situation is in fact like that, that we have major difficulties to get the expected prices. Quite often we only can close the deal when giving heavy discounts. We should try to find a way to make the customers aware of the high value they can expect from us, while at the same time paying a little more than for the competition."

I agree:

"As I am responsible for the objective to offer the latest technology at a premium price, I can all but agree with John's assessment. The reasons for the unpleasant situation are detailed a little more in my assessment of the objective: "Offer latest technology at premium price"."

It is notable that, in the above gauge, unlike the other measures and objectives that have been linked together, it shows that the EVA measure is in excellent standing (the actual EVA (216) was greater that the planned EVA (207), creating a ratio greater than 1, which pushed the gauge into the green). However, all ratios should indicate a trend. What impacts a positive projection for EVA lies in the price premium metric (as shown under customer perspective above). With the need for discount pricing represented by market perception, revenues should be expected to fall which will negatively impact the EVA profit. In this case, the BSC within SEM offers PC4YOU's top management the tools needed to predict the "shockwave" of other perspective's objectives (i.e. the Customer Perspective) on the Financial Perspectives which, in turn, will allow management to refine their initiatives and prevent the negative impact on the Financial Perspective. This is displayed by the management assessment above.

\section{Summary \& Conclusion}

Interest in accounting analysis using SAP, SEM, and the BSC has increased dramatically. The BSC provides a blueprint enabling an organization to achieve desired outcomes by taking concrete actions. One of the advantages of the BSC is that it continually tests the theories underlying management strategies. IF a strategy is not working, it will become evident when the expected outcome is not realized. Corrective actions can be taken to "close to the loop." This iterative process is crucial. If the process is not completed, an organization may drift indefinitely with an ineffective strategy based on faulty assumptions. The emphasis is on progress and continuous improvement.

An important critical success factor in preparing this classroom material is that we have provided the theoretical framework students need to appreciate the link between management strategy and the BSC. The introductory Management Accounting Information Systems I course provides the core managerial accounting concepts required for management decision-making. The subsequent course, Management Accounting information Systems II course then focuses upon technology integration and how SEM provides quick internal information analyses to better define and improve the management strategy. Our objective of increasing students' understanding and appreciation of modern day business is attained through interactive understanding and appreciation of modern day business is attained through interactive computer-base $3 \mathrm{~d}$ learning simulations. Follow-up questionnaires will be administered and the results will be analyzed in an effort to improve pedagogy and thereby enhance student learning. 
An extension of this project could include the development of graduate level materials, perhaps appropriate for an upper-division accounting, strategy or capstone course. The BSC has been used extensively in the Pharmaceutical industry. Case development specific to this industry could provide another teaching method to improve students' decision making and strategy development and implementation skill sets.

\section{References}

1. Brignall, T. J. S. and Ballantine, J. (2004): "Strategic Enterprise Management Systems: new directions for research." Management Accounting Research, volume 15, issue 2, June, pp. 225-240.

2. $\quad$ Davenport, T.H. (1998). "Putting the enterprise into the enterprise system." Harvard Business Review, volume 76, issue 3, pp. 121-131.

3. Fahy, M.J. (2000). "Strategic Enterprise Management: the implications for management accounting and control." paper presented at the $23^{\text {rd }}$ Annual Congress of the European Accounting Association, Munich, March 29-31.

4. Fahy, M., (2001). "Strategic Enterprise Management Systems: Tools for the 21st Century." The Chartered Institute of Management Accountants, London, UK.

5. $\quad$ Rom, A. and Rohde, C. (2006). "Enterprise Resource Planning (ERP) Systems, Strategic Enterprise Management (SEM) Systems and Management Accounting: A Danish Study." Journal of Enterprise Information Management, volume 19, issue 1, pp. 50-66.

6. Kaplan, R.S. and Norton, D.P. (1992), "The balanced scorecard - measures that drive performance," Harvard Business Review, volume 70, issue 1, pp. 71-79.

7. $\quad$ Doyle, P., 1994. "Setting business objectives and measuring performance." European Management Journal. Volume 12 , issue 2, pp. 123-132.

8. Humphrey, C. and Owen, D. (2000). "Debating the power of the audit." International Journal of Auditing. Volume 4, issue, 1, pp. 29-50.

9. Norton, D., SEM Product Management (1999). "SAP Strategic Enterprise Management: Translating Strategy into Action: The Balanced Scorecard." SAP AG.

10. Norreklit, H. (2000). "The balance on the balanced scorecard-a critical analysis of some of its assumptions." Management Accounting Research Journal. Volume 11, issue 1, pp. 65-88.

11. Brignall, T.J. (1997). "A contingent rationale for cost system design in services." Management Accounting Research Journal. Volume 8, issue 3, pp. 325-346.

12. Brignall, T.J. (2002). "The unbalanced scorecard: a social and environmental critique. In: Neely, A., Walters, A., Austin, R. (Eds.),Performance Measurement and Management: Research and Action." Centre for Business Performance, Cranfield School of Management, Cranfield, UK, 17-19 July, pp. 85-92.

13. Whiteside, K. (2002). "The Value of Strategic Enterprise Management." Canadian Underwriter. Volume 69, issue 1, pp. 74 . 


\section{Appendix A}

\section{What Exemplifies Key Markers Used In This Simulation?}

\begin{tabular}{|c|c|c|c|c|c|}
\hline \multicolumn{2}{|c|}{ Perspective } & Objective & Status & Triggering objective & Status \\
\hline \multirow{2}{*}{\multicolumn{2}{|c|}{ Customer Perspective }} & \multirow[t]{2}{*}{ Become a Trusted Advisor } & (I) & Reduce delivery times & $\theta$ \\
\hline & & & & Provide reliable service and support & (9) \\
\hline 8 & very good & Create Image as top innovator & 0 & Offer latest technology at premium price & 3 \\
\hline$\theta$ & good & \multirow[t]{2}{*}{ Offer latest technology at premium price } & 3 & Reduce time to market & (D) \\
\hline (1) & medium & & & Improve patent process & (D) \\
\hline 3 & action required & \multirow[t]{2}{*}{ Provide reliable service and support } & 6 & Reduce quality complaints & $(3)$ \\
\hline (I0I) & unacceptable & & & Integrate distribution with retail partners & 6 \\
\hline \multirow{2}{*}{\multicolumn{2}{|c|}{ s nia }} & Reduce delivery times & 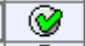 & Improve production planning & 6 \\
\hline & & Reduce quality complaints & 3 & Improve quality management process & (D) \\
\hline \multirow{14}{*}{\multicolumn{2}{|c|}{ Financial Perspective }} & Become most profitable in peer group & 6 & Improve asset utilization & 0 \\
\hline & & Grow revenue from corporate customers & $Q$ & Become a Trusted Advisor & (D) \\
\hline & & Grow revenue from wholesale customers & 9 & Become a Trusted Advisor & (1) \\
\hline & & \multirow[t]{2}{*}{ Grow s ronger than overall market } & (1) & Grow revenue from wholesale customers & 8 \\
\hline & & & & Grow revenue from corporate customers & 8 \\
\hline & & \multirow[t]{2}{*}{ Improve asset utilization } & 0 & Reduce cost of non quality & (1) \\
\hline & & & & Reduce delivery times & 8 \\
\hline & & \multirow[t]{3}{*}{ In each market become at least \# 2} & $(3)$ & Grow stronger than overall market & (D) \\
\hline & & & & Create Image as top innovator & 0 \\
\hline & & & & Offer latest technology at premium price & 8 \\
\hline & & \multirow[t]{3}{*}{ Increase Shareholder Value } & $Q$ & In each market become at least $\# 2$ & 3 \\
\hline & & & & Become most profitable in peer group & 6 \\
\hline & & & & Grow stronger than overall market & (1) \\
\hline & & Reduce cost of non quality & (D) & Reduce quality complaints & 8 \\
\hline \multirow{7}{*}{\multicolumn{2}{|c|}{ Internal Perspective }} & Develop high volume shipment process & 0 & & \\
\hline & & Improve patent process & (1) & Improve R\&D process & (1) \\
\hline & & Improve production planning & 6 & Improve quality management process & (1) \\
\hline & & Improve quality management process & (D) & & \\
\hline & & Improve R\&D process & (1) & Hire talented people & (1) \\
\hline & & Integrate distribution with retail partners & 6 & Develop high volume shipment process & 8 \\
\hline & & Reduce time to market & (D) & Improve R\&D process & (1) \\
\hline \multirow{4}{*}{\multicolumn{2}{|c|}{ Learning \& Growth Perspective }} & Align organization to strategy & Q & & \\
\hline & & Create know how sharing network & 6 & & \\
\hline & & Hire talented people & (D) & & \\
\hline & & Improve technology infrastructure & (D) & & \\
\hline
\end{tabular}




\section{Appendix B}

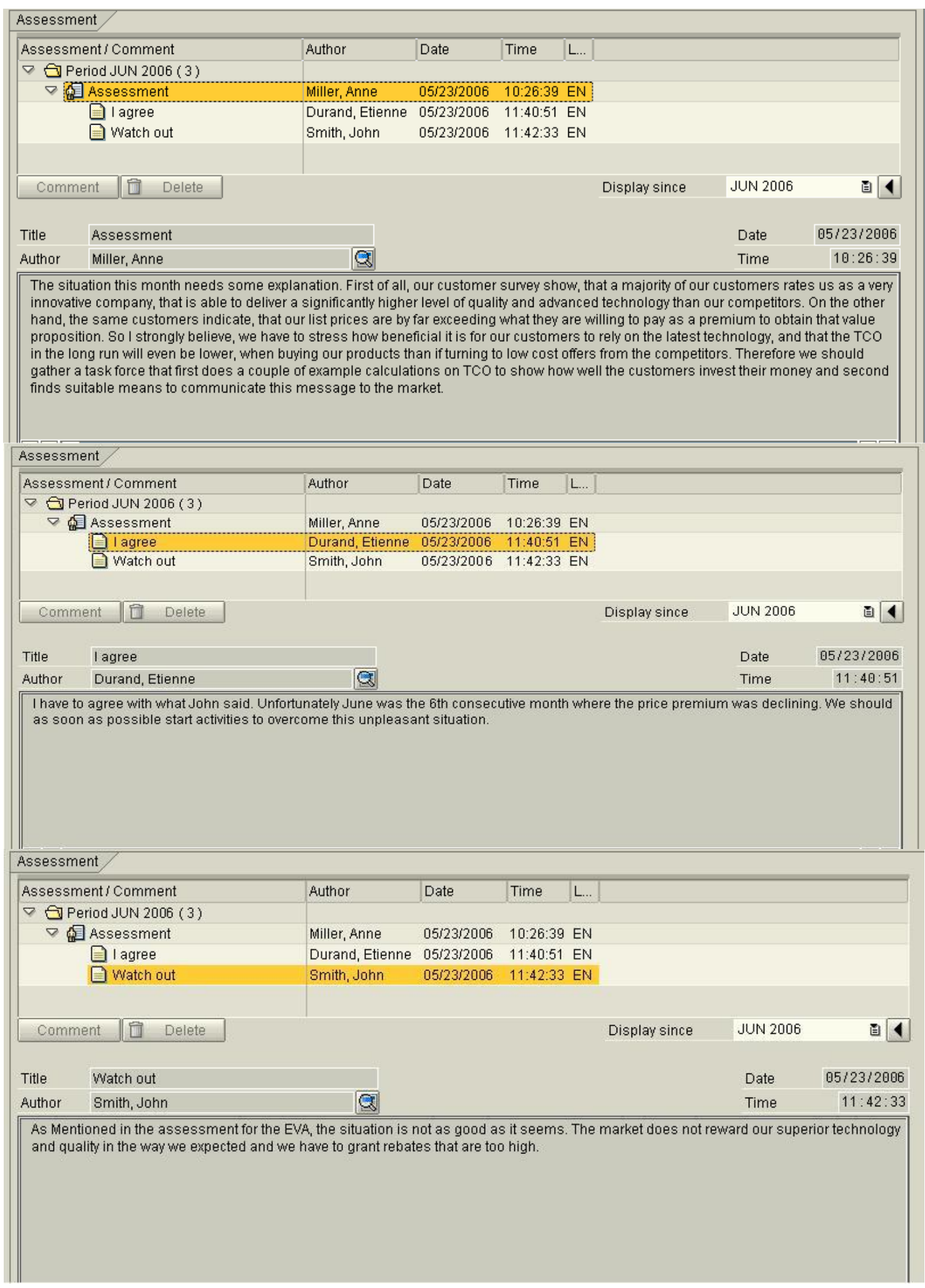




\section{Appendix C}

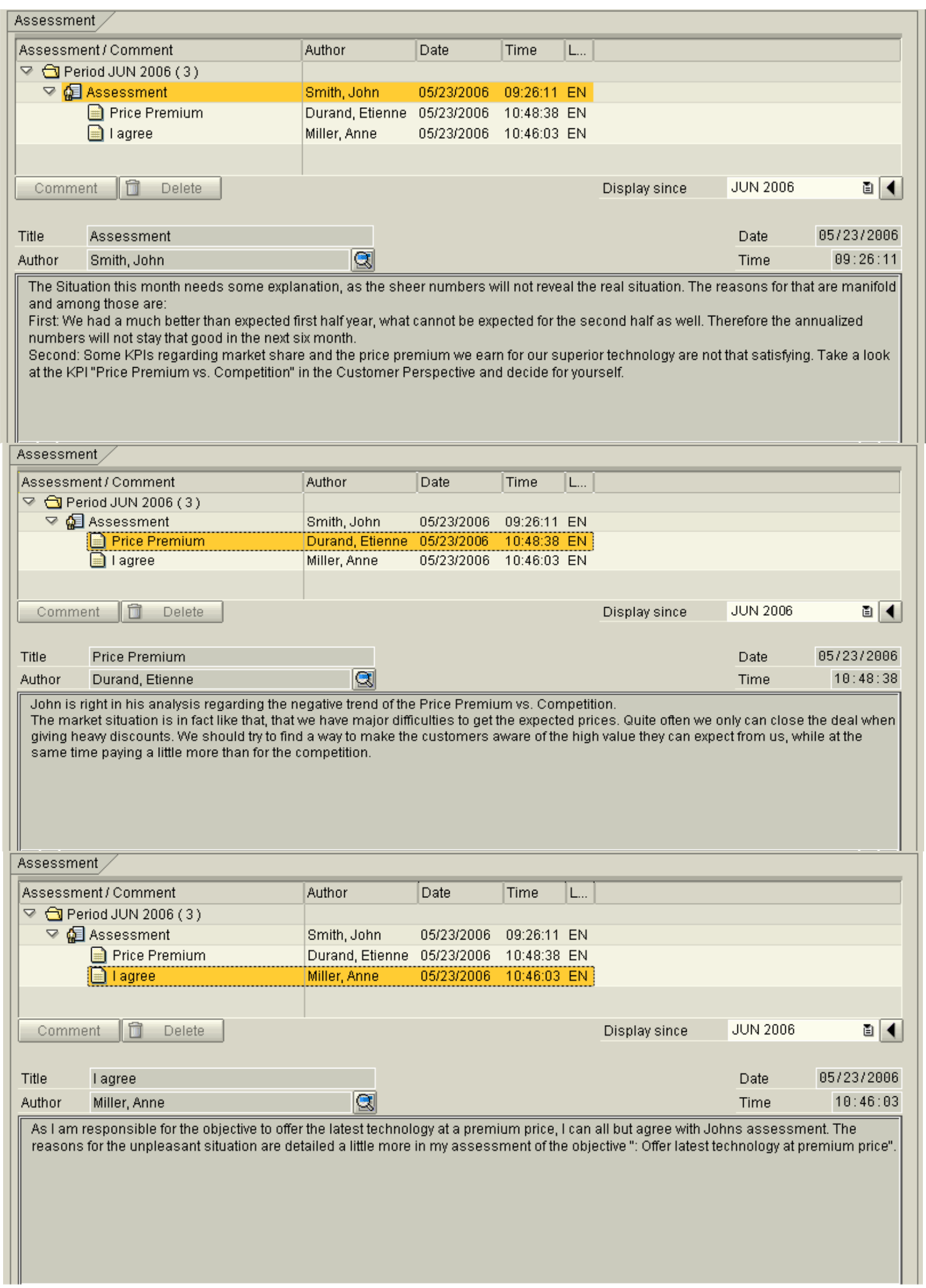

